Article

\title{
Omega-3 Fatty Acid Intake of Pregnant Women and Women of Childbearing Age in the United States: Potential for Deficiency?
}

\author{
Tara M. Nordgren ${ }^{1, *}$, Elizabeth Lyden ${ }^{2}$, Ann Anderson-Berry ${ }^{3}$ and Corrine Hanson 4 \\ 1 Pulmonary, Critical Care, Sleep \& Allergy Division, Department of Internal Medicine, \\ University of Nebraska Medical Center, 985910 Nebraska Medicine, Omaha, NE 68198-5910, USA \\ 2 Biostatistics Department, College of Public Health, University of Nebraska Medical Center, \\ 984375 Nebraska Medical Center, Omaha, NE 68198-4375, USA; elyden@unmc.edu \\ 3 Department of Pediatrics, University of Nebraska Medical Center, 981205 Nebraska Medical Center, Omaha, \\ NE 68198-1205, USA; alanders@unmc.edu \\ 4 Medical Nutrition Education Division, College of Allied Health Professions, \\ University of Nebraska Medical Center, 984045 Nebraska Medical Center, Omaha, NE 68198-4045, USA; \\ ckhanson@unmc.edu \\ * Correspondence: tnordgren@unmc.edu; Tel.: +1-402-559-5536
}

Received: 7 February 2017; Accepted: 22 February 2017; Published: 26 February 2017

\begin{abstract}
Omega-3 fatty acids play critical roles during fetal growth and development with increased intakes associated with improved maternal-fetal outcomes. Omega-3 fatty acid intake in Western diets is low, and the impact of socioeconomic factors on omega-3 fatty acid intake in pregnant women and women of childbearing age has not been reported. We used the National Health and Nutrition Examination Survey (NHANES) cycles 2003-2012 to assess the relationship between omega-3 fatty acid intake and socioeconomic factors in women of childbearing age. Out of 7266 eligible participants, 6478 were women of childbearing age, while 788 were identified as pregnant at the time of the survey. Mean EPA+DHA intake of the population was $89.0 \mathrm{mg}$ with no significant difference between pregnant and non-pregnant women. By univariate and multivariate analyses adjusting for confounders, omega- 3 fatty acid intake was significantly associated with poverty-to-income ratio, race, and educational attainment. Our results demonstrate that omega- 3 fatty acid intake is a concern in pregnant women and women of childbearing age in the United States, and that socioeconomically disadvantaged populations are more susceptible to potential deficiencies. Strategies to increase omega-3 fatty acid intake in these populations could have the potential to improve maternal and infant health outcomes.
\end{abstract}

Keywords: omega-3 fatty acid; women; childbearing; diet; pregnancy; socioeconomic

\section{Introduction}

Maternal diet is critical for a successful pregnancy, as well as fetal health outcomes [1-3]. The hypothesis that early life diet in utero increases the vulnerability of the offspring to the development of poor outcomes and disease is now well accepted [4,5]. Several studies have established that quantity and quality of dietary fats consumed during pregnancy have profound health implications during and after pregnancy [6,7]. Omega-3 fatty acids play critical roles during fetal growth and development, and higher intakes of omega-3 fatty acids during pregnancy have been associated with decreased maternal depression [6], reduced rates of intrauterine growth restriction [6], preterm birth [8-10], reduced allergies and asthma in children [11], and improved neurocognitive outcomes in the offspring [6]. 
Despite the importance of these fatty acids in maternal-fetal health, omega-3 fatty acid intake is typically very low in the Western diet $[12,13]$. Socioeconomic factors have been shown to impact the overall quality of diet, such as intakes of fruits and vegetables [14-18], however the impact of socioeconomic indicators on intake of omega-3 fatty acids is unknown. The National Health and Nutrition Examination Survey (NHANES) contains dietary intake of omega-3 fatty acids, including DHA and EPA, and measures of socioeconomic status, allowing us to evaluate these relationships. Therefore, the objective of this study was to use NHANES data to examine omega-3 fatty acid intake of women of childbearing age in the United States, and to assess the impact of poverty, race, food security, and other socioeconomic factors on omega-3 fatty acid status.

\section{Materials and Methods}

\subsection{Subjects}

Women who were 14-45 years of age and women who were identified as pregnant from NHANES cycles 2003-2012 were included in the analysis (detailed information regarding the collection and analyses of the NHANES datasets are available on the Centers for Disease Control and Prevention website, accessible at http://wwwn.cdc.gov/Nchs/Nhanes/ [19]). Waves earlier than 2003 were not included due to large amounts of missing data (up to $85 \%$ ) on socioeconomic indices. Participants with energy intake greater than or less than the plausible intake ( $<600$ or $>6000 \mathrm{kcal} /$ day $)$ were excluded from the analysis, as were women missing information on pregnancy status. The final number of eligible participants was 7266 .

\subsection{Dietary Assessment}

The main outcome variable was the dietary intake of omega- 3 fatty acids DHA and EPA. The average EPA and DHA intakes for each participant were used to calculate a sum value of the two estimates (EPA+DHA). In other studies, average EPA, DHA, and their summation have been shown to be highly correlated $[20,21]$. However, since DHA is specifically recommended during pregnancy [22,23], we also evaluated DHA and EPA separately.

Dietary intake in the NHANES survey was determined from two interviewer-administered 24-h recalls using methodology developed and validated by the U.S. Department of Agriculture. The dietary recalls were conducted in English or Spanish in study participants who were 12 years and older. Three to 10 days later, all participants were asked to complete a second 24-h dietary recall interview by telephone.

Use of dietary supplements or prenatal vitamins containing omega-3 fatty acids was evaluated through the NHANES supplement files. Supplements containing the ingredient codes matching "alpha-linolenic acid (ALA), omega-3, docosahexaenoic acid (DHA) or eicosapentaenoic acid (EPA)" from the Dietary Supplement Ingredient Database (Release 3) were identified. The identified omega-3 supplements were then matched to the individual's file to create a dichotomous $(\mathrm{Y} / \mathrm{N})$ variable for supplement intake in the last 30 days.

\subsection{Other Covariates}

Poverty-to-income ratio (PIR) was used as an index of socioeconomic status. The PIR is the ratio of household income to the poverty threshold after accounting for inflation and family size [24,25]. The PIR is used to determine eligibility for means-tested government-sponsored assistance programs relevant for women, particularly the Special Supplemental Nutrition Program for Women, Infants, and Children (WIC) [14].

Race/ethnicity was categorized as Hispanic, non-Hispanic white, non-Hispanic Black, and Other (including multi-racial). Education level was categorized as less than high school, high school diploma recipient, or GED (General Educational Development test), and greater than high school education. 
Food insecurity was measured with the 18-item US Food Security Survey Module [26]. Questions are ordered by severity and attribute-related experiences or behaviors to insufficient resources to buy food over the past 12 months. A raw score was created by summing the affirmative responses of the 18 questions, with a higher score reflecting higher concentrations of food insecurity. Categories were then assigned on the basis of guidelines from the USDA: 0 , full food security; 1-2, marginal food security; 3-5 (households without children), or 3-7 (households with children), low food security; and 6-10 (households without children) or 8-18 (households with children), very low food security. Food insecurity refers to households reporting low or very low food security, and we dichotomized food security into yes/no categories. Supplemental Nutrition Assistance Program (SNAP) participation was assessed with the question, "in the last 12 months, did you or any members of your household receive Food Stamp benefits?" Both food insecurity and SNAP participation are measured at the household level.

\subsection{Statistical Analysis}

Descriptive statistics (counts and percentages and means and standard deviations) are shown for all participants. SAS version 9.4 (SAS, Cary, NC, USA) was used for all statistical analyses. Survey procedures in this software package incorporate sample weights and adjust analyses for the complex sample design of the survey. Survey sample weights were used in all analyses to determine estimates that were representative of the U.S. civilian, non-institutionalized population. The SAS procedures PROC SURVEYFREQ, PROC SURVEYMEANS, PROC SURVEYLOGISTIC, and PROC SURVEYREG were used in computing descriptive analysis and doing regression analysis, because these procedures accounted for the weighted data and complex design of the sample. The results of the descriptive analysis for categorical variables are represented by counts, percentages and weighted frequencies. Means, standard errors and 95\% confidence intervals were used for continuous variables. Associations between categorical variables were determined using the Wald chi-square test that accounts for the complex survey design. The $p$-values for the comparisons of continuous data between groups (e.g., omega-3 fatty acid categories and PIR groups) were obtained from "PROC SURVEYREG", a SAS procedure that performs regression analysis for sample survey data. Potential confounding variables were chosen based on prior associations in the literature and significance in the univariate models. The final multivariate model included age, energy intake, race/ethnicity, PIR, NHANES wave, education level, and pregnancy status. A $p$-value of $<0.05$ was considered statistically significant.

\section{Results}

The final number of eligible participants was 7266 . Of these, 6478 were women of childbearing age, while 788 were identified as pregnant at the time of the survey. The demographic characteristics of the sample by pregnancy status are given in Table 1.

There were no differences in DHA, EPA, or DHA+EPA intake between the pregnant and the non-pregnant women ( $p=0.79,0.71$, and 0.75 for DHA, EPA, and DHA+EPA respectively), therefore these populations were combined for analysis of relationships with socioeconomic factors. In the univariate analysis, a statistically significant association was seen between omega-3 fatty acid intake and PIR ( $p=0.03, p=0.03$, and 0.03 for EPA, DHA, and EPA+DHA, respectively). Omega-3 fatty acid intake also differed significantly by NHANES wave (Table 2), race (Table 3), and educational attainment (Table 4). 
Table 1. Participant characteristics by pregnancy status.

\begin{tabular}{|c|c|c|c|}
\hline \multirow{2}{*}{ Characteristic } & Pregnant Women & Non-Pregnant Women & \multirow{2}{*}{$p$-Value } \\
\hline & $(n=788 ; 10.8 \%)$ & $(n=6478 ; 89.2 \%)$ & \\
\hline \multicolumn{4}{|c|}{ Continuous variables: Mean $\left(\mathrm{SE}^{1}\right)$} \\
\hline Age (years) & $28.1(0.33)$ & $31.2(0.18)$ & $<0.0001$ \\
\hline Body Mass Index $\left(\mathrm{kg} / \mathrm{m}^{2}\right)^{2}$ & $29.4(0.37)$ & $27.7(0.15)$ & $<0.0001$ \\
\hline Family PIR (0-18 score) & $2.8(0.11)$ & $2.7(0.04)$ & 0.73 \\
\hline Energy Intake (kcal) & $2144.0(40.86)$ & $2225.3(8.72)$ & $<0.0001$ \\
\hline DHA Intake (mg) & $66.4(0.006)$ & $58.3(0.002)$ & 0.79 \\
\hline EPA Intake (mg) & $34.4(0.004)$ & $30.2(0.002)$ & 0.71 \\
\hline DHA+EPA Intake (mg) & $100.8(0.010)$ & $88.5(0.004)$ & 0.75 \\
\hline \multicolumn{4}{|c|}{ Categorical variables: $n(\%)$} \\
\hline Race & & & \multirow{6}{*}{0.0005} \\
\hline Non-Hispanic White & $317(4.6)$ & $2533(95.4)$ & \\
\hline Hispanic & $268(7.8)$ & $1894(92.2)$ & \\
\hline Non-Hispanic Black & $149(7.3)$ & $1592(92.7)$ & \\
\hline Other Race-Including Multi-Racial & $54(6.8)$ & $459(93.2)$ & \\
\hline Education Level & & & \\
\hline$<\mathrm{HS}$ & $185(1.2)$ & $1057(14.8)$ & \multirow{3}{*}{0.18} \\
\hline HS or equivalent & $141(1.2)$ & $1027(19.4)$ & \\
\hline$<\mathrm{HS}$ & $363(3.6)$ & $2914(60.0)$ & \\
\hline \multicolumn{4}{|l|}{ SNAP Use } \\
\hline Yes & $163(5.5)$ & 1255 (76.2) & \multirow{2}{*}{0.06} \\
\hline No & $10(0.60)$ & $255(17.6)$ & \\
\hline \multicolumn{4}{|l|}{ Food Security Status } \\
\hline Full & $546(4.4)$ & $4212(69.7)$ & \multirow{4}{*}{0.32} \\
\hline Marginal & $98(0.58)$ & $882(9.7)$ & \\
\hline Low & $76(0.44)$ & $772(8.5)$ & \\
\hline Very Low & $48(0.28)$ & $530(6.4)$ & \\
\hline
\end{tabular}

${ }^{1}$ SE: Standard Error; ${ }^{2}$ BMI at time of enrollment in NHANES; values thus represent pregnancy BMI in individuals identifying as pregnant at the time of enrollment.

Table 2. Omega 3 fatty acid intake by NHANES wave ${ }^{1}$.

\begin{tabular}{lllll}
\hline Wave & Variable & $\boldsymbol{n}$ & Mean $\left(\mathrm{SE}^{\mathbf{2}}\right), \mathbf{m g}$ & $\mathbf{9 5 \%}$ CI for Mean \\
\hline \multirow{2}{*}{$2003-2004$} & EPA & 1820 & $27.8(2.7)$ & $22.2,33.2$ \\
& DHA & 1820 & $55.7(4.0)$ & $47.7,63.8$ \\
& EPA+DHA & 1820 & $83.5(6.7)$ & $70.0,97.0$ \\
$2005-2006$ & EPA & 2022 & $40.0(4.3)$ & $31.4,48.6$ \\
& DHA & 2022 & $71.7(6.3)$ & $59.1,84.2$ \\
& EPA+DHA & 2022 & $111.7(10.4)$ & $91.0,130.3$ \\
$2007-2008$ & EPA & 1098 & $26.7(1.9)$ & $23.3,30.4$ \\
& DHA & 1098 & $53.8(3.2)$ & $47.4,60.1$ \\
$2009-2010$ & EPA+DHA & 1098 & $80.6(4.9)$ & $70.7,90.4$ \\
& EPA & 1299 & $35.0(8.3)$ & $18.5,51.5$ \\
$2011-2012$ & DHA & 1299 & $67.1(11.8)$ & $43.5,90.1$ \\
& EPA+DHA & 1299 & $102.1(20.0)$ & $62.2,142.0$ \\
& EPA & 1027 & $20.5(2.3)$ & $16.0,25.0$ \\
& DHA & 1027 & $42.4(3.3)$ & $35.8,48.9$ \\
\hline
\end{tabular}

1 p-Value for EPA intake between waves $=0.0002$, DHA and EPA+DHA both $<0.0001 ;{ }^{2} \mathrm{SE}$ : Standard Error. 
Table 3. Omega-3 fatty acid intake by race ${ }^{1}$.

\begin{tabular}{lllll}
\hline Race/Ethnicity & Variable & $\boldsymbol{n}$ & Mean $\left(\mathbf{S E}^{\mathbf{2}}\right), \mathbf{m g}$ & $\mathbf{9 5 \%}$ CI for Mean \\
\hline \multirow{4}{*}{ Hispanic } & EPA & 2162 & $31.0(3.2)$ & $24.6,37.3$ \\
& DHA & 2162 & $62.5(3.9)$ & $54.6,70.4$ \\
\multirow{4}{*}{ Non-Hispanic White } & EPA+DHA & 2162 & $93.5(7.1)$ & $79.4,107.6$ \\
& EPA & 2850 & $26.6(3.1)$ & $20.4,32.6$ \\
& DHA & 2850 & $51.4(4.1)$ & $43.2,59.5$ \\
Non-Hispanic Black & EPA+DHA & 2850 & $78.0(7.1)$ & $63.8,92.1$ \\
& EPA & 1741 & $38.7(3.5)$ & $31.7,45.6$ \\
Other Race-Including & DHA & 1741 & $73.0(5.2)$ & $62.6,83.2$ \\
Multi-Racial & EPA+DHA & 1741 & $111.7(8.6)$ & $91.7,12.8$ \\
& EPA & 513 & $49.7(4.6)$ & $40.5,58.9$ \\
& DHA & 513 & $91.7(8.1)$ & $75.6,107.9$ \\
& EPA+DHA & 513 & $141.4(12.5)$ & $116.5,166.5$ \\
\hline
\end{tabular}

${ }^{1} p \leq 0.0001$ for EPA, DHA, and EPA+DHA; ${ }^{2}$ SE: Standard Error.

Table 4. Omega-3 fatty acid intake and educational attainment ${ }^{1}$.

\begin{tabular}{|c|c|c|c|c|}
\hline Education & Variable & $n$ & Mean $\left(\mathrm{SE}^{2}\right), \mathrm{mg}$ & $95 \%$ CI for Mean \\
\hline \multirow{4}{*}{$<\mathrm{HS}^{3}$} & EPA & 1242 & $27.1(2.9)$ & $21.2,33.0$ \\
\hline & DHA & 1242 & $56.2(4.4)$ & $47.4,65.0$ \\
\hline & $\mathrm{EPA}+\mathrm{DHA}$ & 1242 & $83.4(7.2)$ & $68.9,97.8$ \\
\hline & EPA & 1168 & $21.58(2.2)$ & $17.1,26.0$ \\
\hline \multirow[t]{3}{*}{$\mathrm{HS} / \mathrm{GED}^{4}$} & DHA & 1168 & $44.0(3.1)$ & $37.7,50.3$ \\
\hline & $\mathrm{EPA}+\mathrm{DHA}$ & 1168 & $65.6(5.2)$ & $55.2,76.0$ \\
\hline & EPA & 3277 & $35.7(3.3)$ & $29.2,42.3$ \\
\hline \multirow[t]{2}{*}{$>\mathrm{HS}$} & DHA & 3277 & $66.9(4.5)$ & $57.8,76.0$ \\
\hline & $\mathrm{EPA}+\mathrm{DHA}$ & 3277 & $102.7(7.8)$ & $87.1,118.3$ \\
\hline
\end{tabular}

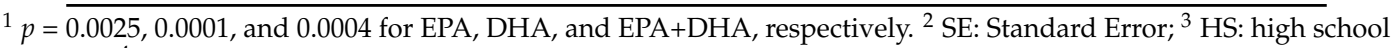
diploma; ${ }^{4}$ GED: General Educational Development test.

There was no association between omega- 3 fatty acid intake and food security $(p=0.17,0.12$, and 0.14 for EPA, DHA, and EPA+DHA, respectively) or SNAP use ( $p=0.71,0.58$, and 0.62 for EPA, DHA, and EPA+DHA, respectively).

After adjusting for relevant confounders, including age, BMI, energy intake, pregnancy status and NHANES wave, significant associations were maintained between PIR, race and education level and intake of DHA, EPA, and DHA+EPA. The significant results of the multivariate regression models are shown in Table 5.

Table 5. Results of multivariate regression models of socioeconomic indicators and omega-3 fatty acid intake ${ }^{1}$.

\begin{tabular}{lcccccc}
\hline \multirow{2}{*}{ Socioeconomic Indicator } & \multicolumn{2}{c}{ EPA (mg) } & \multicolumn{2}{c}{ DHA (mg) } & \multicolumn{2}{c}{ EPA+DHA (mg) } \\
\cline { 2 - 7 } & $\boldsymbol{\beta}$ & $\boldsymbol{p}$-Value & $\beta$ & $p$-Value & $\beta$ & $p$-Value \\
\hline Poverty-Income Ratio (PIR) & 3.1 & 0.03 & 4.5 & 0.03 & 7.6 & 0.03 \\
Educational Attainment & & & & & & \\
< HS ${ }^{2}$ vs. $>$ HS & -6.4 & 0.09 & -9.2 & 0.08 & -15.5 & 0.08 \\
HS $/$ GED $^{3}$ vs. $>$ HS & -11.5 & 0.0003 & -19.6 & $<0.0001$ & -31.0 & $<0.0001$ \\
Race & & & & & & \\
$\quad$ Non-Hispanic White vs. Black & 17.8 & $<0.0001$ & 30.4 & $<0.0001$ & 48.2 & $<0.0001$ \\
Non-Hispanic White vs. Hispanic & 11.8 & 0.01 & 23.4 & 0.0001 & 35.3 & 0.001 \\
$\quad$ Non-Hispanic White vs. Other & 24.0 & 0.0001 & 42.4 & $<0.0001$ & 66.5 & $<0.0001$ \\
\hline
\end{tabular}

${ }^{1}$ Models adjusted for age, BMI, energy intake, and NHANES wave. ${ }^{2}$ HS: high school diploma; ${ }^{3}$ GED: General Educational Development test. 
When the proportion of women who use a dietary supplement containing omega- 3 fatty acids was evaluated, $5.7 \%$ of all participants took an omega- 3 containing supplement, while $94.3 \%$ of participants did not. Omega-3 fatty acid-containing supplement usage was significantly associated with pregnancy status, poverty-to-income ratio, educational attainment, and race, as shown in Table 6.

Table 6. Omega-3 fatty acid-containing supplement usage.

\begin{tabular}{|c|c|c|c|}
\hline Omega-3 Supplement Usage & $n$ & Percent & $p$ Value \\
\hline \multicolumn{4}{|l|}{ Pregnancy Status } \\
\hline \multicolumn{4}{|l|}{ Not Pregnant } \\
\hline Yes & 85 & 1.8 & \multirow{4}{*}{$<0.0001$} \\
\hline No & 6388 & 98.2 & \\
\hline \multicolumn{4}{|l|}{ Pregnant } \\
\hline Yes & 24 & 9.0 & \\
\hline No & 764 & 91.0 & \\
\hline \multicolumn{4}{|l|}{ PIR Ratio } \\
\hline \multicolumn{4}{|l|}{$\mathrm{PIR} \leq 1.85$} \\
\hline Yes & 33 & 1.2 & \\
\hline No & 3484 & 98.8 & \\
\hline \multicolumn{4}{|l|}{$\mathrm{PIR}>1.85$} \\
\hline Yes & 71 & 2.9 & \multirow{2}{*}{0.0003} \\
\hline No & 3270 & 97.1 & \\
\hline \multicolumn{4}{|l|}{$\begin{array}{l}\text { Educational Attainment } \\
\end{array}$} \\
\hline \multicolumn{4}{|l|}{$<\mathrm{HS}^{1}$} \\
\hline Yes & 7 & 0.9 & \\
\hline \multirow{2}{*}{\multicolumn{4}{|c|}{$\mathrm{HS} / \mathrm{GED}^{2}$}} \\
\hline & & & \\
\hline Yes & 16 & 1.5 & \\
\hline No & 1151 & 98.5 & \\
\hline \multicolumn{4}{|l|}{$>\mathrm{HS}$} \\
\hline Yes & 82 & 3.0 & \multirow{2}{*}{0.0048} \\
\hline No & 3193 & 97.0 & \\
\hline \multicolumn{4}{|l|}{ Race/Ethnicity } \\
\hline \multicolumn{4}{|l|}{ Hispanic } \\
\hline Yes & 25 & 1.6 & \\
\hline No & 2137 & 98.4 & \\
\hline \multicolumn{4}{|l|}{ Non-Hispanic White } \\
\hline Yes & 53 & 2.4 & \\
\hline No & 2796 & 97.6 & \\
\hline \multicolumn{4}{|l|}{ Non-Hispanic Black } \\
\hline Yes & 12 & 0.7 & \\
\hline No & 1727 & 99.3 & \\
\hline \multicolumn{4}{|l|}{ Other-Including Multi-Racial } \\
\hline Yes & 19 & 4.3 & \\
\hline No & 492 & 95.7 & 0.0014 \\
\hline
\end{tabular}

${ }^{1}$ HS: high school diploma; ${ }^{2}$ GED: General Educational Development test.

\section{Discussion}

This study is the first to examine a wide range of socioeconomic indicators on the intake of omega-3 fatty acids in a nationally representative sample of pregnant women and women of childbearing age. Our study shows that lower poverty status, race, and lower educational attainment increase the risk of suboptimal intake of these essential compounds.

Daily intake recommendations for omega- 3 fatty acids vary widely, and recommended daily allowance or dietary reference intakes have not been set for DHA or EPA. The exclusion of DHA and EPA from the dietary reference intakes issues by the Institute of Medicine of the National Academies is largely due to the limited evidence for quantity-based effects of the fatty acids that was available in the 1990s and early 2000s [12]. However, many studies performed in more recent years have demonstrated 
the healthful benefits of these fatty acids, and numerous groups have issued recommendations for omega-3 fatty acid intakes based on age, health, and other factors [12,23]. The members of the Workshop on the Essentiality of and Recommended Dietary Intakes for Omega- 6 and Omega-3 Fatty Acid in 1999 recommended an adequate intake level of DHA+EPA in adults to be at least $650 \mathrm{mg} /$ day, including at least $220 \mathrm{mg}$ /day each of DHA and EPA, with DHA intake in pregnant and lactating women increased to at least $300 \mathrm{mg} /$ day [23]. Other organizations have given similar recommendations, with the World Health Organization suggesting 200-500 mg/day of EPA+DHA [27], and numerous organizations encouraging two servings of fatty fish per week to reach an approximately $450-500 \mathrm{mg} /$ day allowance [12]. Variation in these recommended levels are likely due to the wide range of dosing that have been used in clinical studies investigating the beneficial actions of these fatty acids, although the recommendations do indicate a general consensus suggesting a minimum requirement of $200 \mathrm{mg} /$ day of EPA+DHA. Despite these recommendations, a study of the 1999-2000 NHANES data indicated average intake of $100 \mathrm{mg} /$ day in the United States population [13]. Our findings indicate that in women of childbearing age, average intake of DHA+EPA is $89 \mathrm{mg} /$ day. Mean DHA+EPA intake of men between the same age range of 14-45 years was $119 \mathrm{mg} /$ day, significantly increased compared to women $(p<0.001)$. While we did find statistically significant differences in DHA and EPA intake based on NHANES wave (Table 2), we are not certain that these differences are of clinical significance, giving their low overall values compared with the discussed recommended values. Furthermore, intake of DHA, recommended to be at least $300 \mathrm{mg} /$ day in pregnant women, was not significantly different between pregnant and non-pregnant women, and was only $66 \mathrm{mg} /$ day in pregnant women and $58 \mathrm{mg} /$ day in non-pregnant women of childbearing age. While these intake values did not include supplementation, our findings from these NHANES surveys indicate only $1.8 \%$ of non-pregnant and $9.0 \%$ of pregnant women took supplements containing EPA and/or DHA.

Furthermore, our data indicate that socioeconomically disadvantaged populations are particularly at risk for even lower levels of omega- 3 intake. With increasing poverty, our data indicate decreased omega-3 fatty acid intake in women of childbearing age, regardless of pregnancy status $(p=0.02)$, and women with educational attainment beyond a high school diploma have an average EPA+DHA intake of $103 \mathrm{mg} /$ day, while women with a high school diploma as highest degree or not achieving a high school diploma had average intakes of $66 \mathrm{mg} /$ day and $83 \mathrm{mg} /$ day, respectively $(p=0.0004)$. Race was also significantly associated with omega-3 fatty acid intake $(p<0.0001)$; non-Hispanic white women of childbearing age had the lowest intake of EPA+DHA, averaging $78 \mathrm{mg} /$ day compared to Hispanic women (94 mg/day), non-Hispanic Black women (112 mg/day), and women of other races, including multi-racial (142 mg/day). These findings indicate numerous risk factors for insufficient omega-3 fatty acid intake in pregnant women and women of childbearing age when compared to suggested intake values $[12,23]$.

Omega-3 supplementation in mothers and infants is associated with numerous positive health outcomes in mother and child [6,28]. Higher intake of omega-3 fatty acids in mothers is associated with reduced risk for depression and intrauterine growth restriction, increased infant birth weight, as well as reduced risk of preterm birth [6-10]. Numerous studies have found improved developmental and cognitive outcomes in infants and children with high or supplemented omega-3 fatty acid intake (including maternal intake), including increases in visual acuity and problem solving $[6,29,30]$. Although some endogenous synthesis of DHA from dietary fatty acid precursors EPA and ALA can occur, the primary source for fetal and infant DHA intake is dependent on maternal intake [28,31,32]. Specifically, maternal DHA stores are mobilized in the third trimester of pregnancy, and placental transfer of DHA is preferential to other fatty acids, including arachidonic acid and EPA [28]. Through the first two years of a child's life, high levels of DHA are preferentially incorporated into the infant brain [28]. In this early timespan, much of an infant's omega-3 intake is from maternal stores during pregnancy and in breastmilk or formula [33-35]. A breastfed infant's red blood cell membrane DHA content, an indicator of intake, is associated with mother's omega-3 fatty acid intake [35], corroborating the relationship between maternal and child omega-3 statuses. 
The mechanisms underlying the beneficial effects of omega-3 fatty acids are not completely understood. Although, emerging research reveals the role of these lipids in the biosynthesis of bioactive signaling molecules [36]. Following uptake of long-chain polyunsaturated fatty acids into cell phospholipid membranes, signaling events activate the cleavage of these lipids from the membrane to serve as substrates for the biosynthesis of signaling molecules [37-39]. In this regard, the incorporation of these fatty acids into membranes provides pools of substrate for future cell responses, and membrane incorporation is based on dietary availability [38]. Of interest, while the omega-6 fatty acid arachidonic acid serves as the substrate for a number of pro-inflammatory lipid mediators, including prostaglandins and leukotrienes, EPA and DHA are substrates for the production of lipid mediators, including resolvins, protectins, and maresins, that are involved in the active regulation of inflammation resolution and repair processes [36,40-42]. These omega-3 fatty acid-derived pro-resolving mediators have been found in high levels in breastmilk ( 100-fold increase in breastmilk compared to plasma [43]), suggesting a biological role for the mediators in infant health or development $[43,44]$. These findings imply the value of omega-3 intake in maternal and infant diets, although additional studies are needed to identify the association between omega-3 fatty acid intake, pro-resolving lipid mediator production, and the beneficial effects to mother and child.

Recent studies have raised concerns regarding nutrient intake in the United States, especially with nutrients that are of concern during pregnancy. Data from 2003-2008 NHANES cycles demonstrate that women of childbearing age in the United States are not meeting nutrient guidelines for several nutrients, with distinct differences present between ethnic groups and socioeconomic strata $[14,45,46]$. Lower income individuals consumed lower quality foods when compared to those with higher incomes as measured by the Alternate Healthy Eating Index, which includes omega-3 fatty acid intake as one of the components of a healthy diet [47]. Many pregnant women and women of childbearing age have also been shown to consume less than the recommended servings of seafood per week [48]. As reviewed by Makrides et al., studies consistently show improved infant birth weights in women taking omega-3 fatty acid supplements, regardless of income status [7]. Additional work is necessary to clarify the effect of socioeconomic status on omega-3 fatty acid-associated neurocognitive outcomes in infants, but data indicate improved neurobehavioral outcomes in preterm infants when mothers were supplemented while producing milk [7].

Multiple factors contribute to low-income individuals having high risk of poor quality diet, including lack of access to grocery stores and high cost of healthy foods [16]. Individuals in the lowest income households are the least likely to consume vegetables and fruits $[15,17,18]$, and are more likely to consume foods high in fat and sugar and low in fiber $[17,18]$. This data raises significant concerns that access to foods with high nutrient density is not evenly distributed, and as a result, there are likely populations at risk for nutritional deficiencies.

Use of prenatal vitamins may not be a contributing factor toward closing the gap by socioeconomic group, as pre-conception use of multivitamins in the United States is often poor. Our findings indicate only $1.8 \%$ of non-pregnant women of childbearing age use omega- 3 fatty acid-containing supplements. Furthermore, the inclusion of omega- 3 fatty acids in prenatal vitamins is not standard, despite being identified as an important nutrient in pregnant women [22,23]. Furthermore, there is precedence for the need for sufficient omega-3 fatty acid intake both prior to and during pregnancy; numerous studies have investigated the bioavailability and incorporation kinetics of omega- 3 fatty acids in serum, red blood cell lipid membranes, and various tissues [49-53]. Tissue uptake kinetics indicate EPA half-maximal levels in blood rise rapidly (3-5 days) and reach half-maximal red blood cell membrane incorporation in one month [49], but DHA incorporation kinetics are slower and more erratic [49]. In pregnant women, supplementation initiated during pregnancy with $100 \mathrm{mg} /$ day DHA [54] or $185 \mathrm{mg}$ /day DHA [55] did not impact cord blood omega-3 fatty acid composition; higher levels, ranging from 528-2700 grams/day of omega-3 or DHA supplementation during pregnancy have been shown to increase cord blood omega-3 fatty acid incorporation [55-57]. It has been posited that due to fat mobilization during the third trimester of pregnancy, supplementation with 
omega-3 fatty acids may not be necessary to ensure neonate sufficiency [58]. However, findings suggest omega-3 fatty acid incorporation into fat takes longer than red blood cell incorporation, with half-maximal uptakes of DHA and EPA by adipose tissue greater than one year during continuous daily supplementation [49]. Furthermore, maternal and neonatal PUFA statuses are correlated $[59,60]$ , and typical dietary consumption patterns of omega-3 fatty acids by women of childbearing age significantly impacts maternal omega-3 fatty acid status during pregnancy and correlates with infant status at birth [60]. Although lower-dose omega-3 fatty acid supplementation during pregnancy may not alter cord blood omega-3 status, it could limit the typical decline of maternal DHA status during the third trimester of pregnancy [54]. This is of clear value to the mother; additionally, maternal DHA stores recover slowly following birth, and data indicate that successive pregnancies and infants reflect the maternal depleted status with maternal and infant omega-3 fatty acid levels significantly lower in subsequent pregnancies $[59,61]$. Together, these data support the importance of omega-3 fatty acid dietary intake in women of childbearing age, including prior to, during, and following pregnancy.

Our study has several limitations. The cross-sectional nature of NHANES makes it difficult to infer any causation, and it is also possible that confounding occurred from variables not considered in our analysis. Additionally, dietary intake in NHANES is based on two 24-h recalls, which may not be representative of usual intake, as day-to-day intake of specific food items like fish can be highly variable. However, a single 24-h recall is considered adequate for estimates of group means [62].

\section{Conclusions}

Our results demonstrate that omega-3 fatty acid intake in pregnant women and women of childbearing age may be a concern in socioeconomically disadvantaged populations of the United States. More research is needed to determine what type of interventions will be best for specific populations, especially the low-income populations that bear a greater burden of poor diet quality and adverse maternal-child outcomes. As the population of the United States becomes more diverse, issues regarding health and disparities in diet become even more salient.

Acknowledgments: These investigations were supported in part by the following grant mechanism: NIEHS K99 ES025819 (TMN).

Author Contributions: T.M.N., C.H. and A.A.B. conceived of and pursued the research hypothesis and investigations. E.L. performed all statistical analyses associated with the investigations. T.M.N., C.H., E.L. and A.A.B. cooperatively wrote and edited the manuscript and approved the final manuscript.

Conflicts of Interest: The authors declare no conflict of interest.

\section{References}

1. Grieger, J.A.; Clifton, V.L. A Review of the Impact of Dietary Intakes in Human Pregnancy on Infant Birthweight. Nutrients 2014, 7, 153-178. [CrossRef] [PubMed]

2. Akerele, O.A.; Chema, S.K. A Balance of Omega-3 and Omega-6 Polyunsaturated Fatty Acids is Important in Pregnancy. J. Nutr. 2016, 5, 23-33. [CrossRef]

3. Hollins-Martin, C.; Van Den Akker, O.; Martin, C. Handbook of Diet and Nutrition in the Menstrual Cycle. Periconception and Fertility; Wageningen Academic Publishers: Wageningen, The Netherlands, 2014.

4. Laker, R.C.; Wlodek, M.E.; Connelly, J.J.; Yan, Z. Epigenetic Origins of Metabolic Disease: The Impact of the Maternal Condition to the Offspring Epigenome and Later Health Consequences. Food Sci. Hum. Wellness 2013, 2, 1-11. [CrossRef]

5. Perera, F.; Herbstman, J. Prenatal Environmental Exposures, Epigenetics, and Disease. Reprod. Toxicol. 2011, 31, 363-373. [CrossRef] [PubMed]

6. Emmett, P.M.; Jones, L.R.; Golding, J. Pregnancy Diet and Associated Outcomes in the Avon Longitudinal Study of Parents and Children. Nutr. Rev. 2015, 73, 154-174. [CrossRef] [PubMed]

7. Makrides, M.; Collins, C.T.; Gibson, R.A. Impact of Fatty Acid Status on Growth and Neurobehavioural Development in Humans. Matern. Child Nutr. 2011, 7, 80-88. [CrossRef] [PubMed] 
8. Olsen, S.F.; Secher, N.J. Low Consumption of Seafood in Early Pregnancy as a Risk Factor for Preterm Delivery: Prospective Cohort Study. BMJ 2002, 324, 447. [CrossRef] [PubMed]

9. Olsen, S.F.; Osterdal, M.L.; Salvig, J.D.; Weber, T.; Tabor, A.; Secher, N.J. Duration of Pregnancy in Relation to Fish Oil Supplementation and Habitual Fish Intake: A Randomised Clinical Trial with Fish Oil. Eur. J. Clin. Nutr. 2007, 61, 976-985. [CrossRef] [PubMed]

10. Olsen, S.F.; Secher, N.J. A Possible Preventive Effect of Low-Dose Fish Oil on Early Delivery and Pre-Eclampsia: Indications from a 50-Year-Old Controlled Trial. Br. J. Nutr. 1990, 64, 599-609. [CrossRef] [PubMed]

11. Miyata, J.; Arita, M. Role of Omega-3 Fatty Acids and their Metabolites in Asthma and Allergic Diseases. Allergol. Int. 2015, 64, 27-34. [CrossRef] [PubMed]

12. Kris-Etherton, P.M.; Grieger, J.A.; Etherton, T.D. Dietary Reference Intakes for DHA and EPA. Prostaglandins Leukot. Essent. Fatty Acids 2009, 81, 99-104. [CrossRef] [PubMed]

13. Ervin, R.B.; Wright, J.D.; Wang, C.Y.; Kennedy-Stephenson, J. Dietary Intake of Fats and Fatty Acids for the United States Population: 1999-2000. Adv. Data 2004, 348, 1-6.

14. Rai, D.; Bird, J.K.; McBurney, M.I.; Chapman-Novakofski, K.M. Nutritional Status as Assessed by Nutrient Intakes and Biomarkers among Women of Childbearing Age-Is the Burden of Nutrient Inadequacies Growing in America? Public Health Nutr. 2015, 18, 1658-1669. [CrossRef] [PubMed]

15. Leung, C.W.; Ding, E.L.; Catalano, P.J.; Villamor, E.; Rimm, E.B.; Willett, W.C. Dietary Intake and Dietary Quality of Low-Income Adults in the Supplemental Nutrition Assistance Program. Am. J. Clin. Nutr. 2012, 96, 977-988. [CrossRef] [PubMed]

16. Karp, R.J.; Wong, G.; Orsi, M. Demonstrating Nutrient Cost Gradients: A Brooklyn Case Study. Int. J. Vitam. Nutr. Res. 2014, 84, 244-251. [CrossRef] [PubMed]

17. Grimm, K.A.; Foltz, J.L.; Blanck, H.M.; Scanlon, K.S. Household Income Disparities in Fruit and Vegetable Consumption by State and Territory: Results of the 2009 Behavioral Risk Factor Surveillance System. J. Acad. Nutr. Diet. 2012, 112, 2014-2021. [CrossRef] [PubMed]

18. Dubowitz, T.; Heron, M.; Bird, C.E.; Lurie, N.; Finch, B.K.; Basurto-Davila, R.; Hale, L.; Escarce, J.J. Neighborhood Socioeconomic Status and Fruit and Vegetable Intake among Whites, Blacks, and Mexican Americans in the United States. Am. J. Clin. Nutr. 2008, 87, 1883-1891. [PubMed]

19. Centers for Disease Control and Prevention. National Health and Nutrition Examination Survey. 2016. Accessible online: https://wwwn.cdc.gov/Nchs/Nhanes/ (accessed on 15 July 2016).

20. Patel, D.; Thevenet-Morrison, K.; van Wijngaarden, E. Omega-3 Polyunsaturated Fatty Acid Intake through Fish Consumption and Prostate Specific Antigen Level: Results from the 2003 to 2010 National Health and Examination Survey. Prostaglandins Leukot. Essent. Fatty Acids 2014, 91, 155-160. [CrossRef] [PubMed]

21. Hoffmire, C.A.; Block, R.C.; Thevenet-Morrison, K.; van Wijngaarden, E. Associations between Omega-3 Poly-Unsaturated Fatty Acids from Fish Consumption and Severity of Depressive Symptoms: An Analysis of the 2005-2008 National Health and Nutrition Examination Survey. Prostaglandins Leukot. Essent. Fatty Acids 2012, 86, 155-160. [CrossRef] [PubMed]

22. Greenberg, J.A.; Bell, S.J.; Ausdal, W.V. Omega-3 Fatty Acid Supplementation during Pregnancy. Rev. Obstet. Gynecol. 2008, 1, 162-169. [PubMed]

23. Simopoulos, A.P.; Leaf, A.; Salem, N., Jr. Workshop Statement on the Essentiality of and Recommended Dietary Intakes for Omega-6 and Omega-3 Fatty Acids. Prostaglandins Leukot. Essent. Fatty Acids 2000, 63, 119-121. [CrossRef] [PubMed]

24. Ogden, C.L.; Lamb, M.M.; Carroll, M.D.; Flegal, K.M. Obesity and Socioeconomic Status in Children and Adolescents: United States, 2005-2008. NCHS Data Brief. 2010, 51, 1-8.

25. Ogden, C.L.; Lamb, M.M.; Carroll, M.D.; Flegal, K.M. Obesity and Socioeconomic Status in Adults: United States, 2005-2008. NCHS Data Brief 2010, 51, 1-8.

26. U.S. Department of Agriculture Food and Nutrition Service. Guide to Measuring Household Food Security. 2000. Available online: http://hungerfreecommunities.org/wp-content/uploads/2011/04/USDA-guideto-measuring-food-security.pdf (accessed on 25 August 2016).

27. World Health Organization. Diet, Nutrition and the Prevention of Chronic Diseases; WHO: Geneva, Switzerland, 2003.

28. Lauritzen, L.; Brambilla, P.; Mazzocchi, A.; Harslof, L.B.; Ciappolino, V.; Agostoni, C. DHA Effects in Brain Development and Function. Nutrients 2016, 8, 6. [CrossRef] [PubMed] 
29. Uauy, R.; Hoffman, D.R.; Mena, P.; Llanos, A.; Birch, E.E. Term Infant Studies of DHA and ARA Supplementation on Neurodevelopment: Results of Randomized Controlled Trials. J. Pediatr. 2003, 143, 17-25. [CrossRef]

30. Campoy, C.; Escolano-Margarit, M.V.; Anjos, T.; Szajewska, H.; Uauy, R. Omega 3 Fatty Acids on Child Growth, Visual Acuity and Neurodevelopment. Br. J. Nutr. 2012, 107, 85-106. [CrossRef] [PubMed]

31. Clandinin, M.T.; Chappell, J.E.; Leong, S.; Heim, T.; Swyer, P.R.; Chance, G.W. Intrauterine Fatty Acid Accretion Rates in Human Brain: Implications for Fatty Acid Requirements. Early Hum. Dev. 1980, 4, 121-129. [CrossRef]

32. Sauerwald, T.U.; Hachey, D.L.; Jensen, C.L.; Chen, H.; Anderson, R.E.; Heird, W.C. Intermediates in Endogenous Synthesis of C22:6 Omega 3 and C20:4 Omega 6 by Term and Preterm Infants. Pediatr. Res. 1997, 41, 183-187. [CrossRef] [PubMed]

33. Jorgensen, M.H.; Nielsen, P.K.; Michaelsen, K.F.; Lund, P.; Lauritzen, L. The Composition of Polyunsaturated Fatty Acids in Erythrocytes of Lactating Mothers and their Infants. Matern. Child Nutr. 2006, 2, $29-39$. [CrossRef] [PubMed]

34. Koletzko, B.; Schmidt, E.; Bremer, H.J.; Haug, M.; Harzer, G. Effects of Dietary Long-Chain Polyunsaturated Fatty Acids on the Essential Fatty Acid Status of Premature Infants. Eur. J. Pediatr. 1989, 148, 669-675. [CrossRef] [PubMed]

35. Makrides, M.; Neumann, M.A.; Byard, R.W.; Simmer, K.; Gibson, R.A. Fatty Acid Composition of Brain, Retina, and Erythrocytes in Breast- and Formula-Fed Infants. Am. J. Clin. Nutr. 1994, 60, 189-194. [PubMed]

36. Serhan, C.N. Pro-Resolving Lipid Mediators are Leads for Resolution Physiology. Nature 2014, 510, 92-101. [CrossRef] [PubMed]

37. Levy, B.D. Resolvins and Protectins: Natural Pharmacophores for Resolution Biology. Prostaglandins Leukot. Essent. Fatty Acids 2010, 82, 327-332. [CrossRef] [PubMed]

38. Raphael, W.; Sordillo, L.M. Dietary Polyunsaturated Fatty Acids and Inflammation: The Role of Phospholipid Biosynthesis. Int. J. Mol. Sci. 2013, 14, 21167-21188. [CrossRef] [PubMed]

39. Bannenberg, G.; Serhan, C.N. Specialized Pro-Resolving Lipid Mediators in the Inflammatory Response: An Update. Biochim. Biophys. Acta 2010, 1801, 1260-1273. [CrossRef] [PubMed]

40. Basil, M.C.; Levy, B.D. Specialized Pro-Resolving Mediators: Endogenous Regulators of Infection and Inflammation. Nat. Rev. Immunol. 2016, 16, 51-67. [CrossRef] [PubMed]

41. Patterson, E.; Wall, R.; Fitzgerald, G.F.; Ross, R.P.; Stanton, C. Health Implications of High Dietary Omega-6 Polyunsaturated Fatty Acids. J. Nutr. Metab. 2012, 2012. [CrossRef] [PubMed]

42. Weylandt, K.H.; Chiu, C.Y.; Gomolka, B.; Waechter, S.F.; Wiedenmann, B. Omega-3 Fatty Acids and their Lipid Mediators: Towards an Understanding of Resolvin and Protectin Formation. Prostaglandins Other Lipid Mediat. 2012, 97, 73-82. [CrossRef] [PubMed]

43. Weiss, G.A.; Troxler, H.; Klinke, G.; Rogler, D.; Braegger, C.; Hersberger, M. High Levels of Anti-Inflammatory and Pro-Resolving Lipid Mediators Lipoxins and Resolvins and Declining Docosahexaenoic Acid Levels in Human Milk during the First Month of Lactation. Lipids Health. Dis. 2013, 12, 89. [CrossRef] [PubMed]

44. Arnardottir, H.; Orr, S.K.; Dalli, J.; Serhan, C.N. Human Milk Proresolving Mediators Stimulate Resolution of Acute Inflammation. Mucosal Immunol. 2016, 9, 757-766. [CrossRef] [PubMed]

45. Krebs-Smith, S.M.; Guenther, P.M.; Subar, A.F.; Kirkpatrick, S.I.; Dodd, K.W. Americans do Not Meet Federal Dietary Recommendations. J. Nutr. 2010, 140, 1832-1838. [CrossRef] [PubMed]

46. Fulgoni, V.L., III; Keast, D.R.; Bailey, R.L.; Dwyer, J. Foods, Fortificants, and Supplements: Where do Americans Get their Nutrients? J. Nutr. 2011, 141, 1847-1854. [CrossRef] [PubMed]

47. Wang, D.D.; Leung, C.W.; Li, Y.; Ding, E.L.; Chiuve, S.E.; Hu, F.B.; Willett, W.C. Trends in Dietary Quality among Adults in the United States, 1999 through 2010. JAMA Intern. Med. 2014, 174, 1587-1595. [CrossRef] [PubMed]

48. Razzaghi, H.; Tinker, S.C. Seafood Consumption among Pregnant and Non-Pregnant Women of Childbearing Age in the United States, NHANES 1999-2006. Food Nutr. Res. 2014, 11, 58. [CrossRef] [PubMed]

49. Katan, M.B.; Deslypere, J.P.; van Birgelen, A.P.; Penders, M.; Zegwaard, M. Kinetics of the Incorporation of Dietary Fatty Acids into Serum Cholesteryl Esters, Erythrocyte Membranes, and Adipose Tissue: An 18-Month Controlled Study. J. Lipid Res. 1997, 38, 2012-2022. [PubMed] 
50. Gurzell, E.A.; Wiesinger, J.A.; Morkam, C.; Hemmrich, S.; Harris, W.S.; Fenton, J.I. Is the Omega-3 Index a Valid Marker of Intestinal Membrane Phospholipid EPA+DHA Content? Prostaglandins Leukot. Essent. Fatty Acids 2014, 91, 87-96. [CrossRef] [PubMed]

51. Bronsgeest-Schoute, H.C.; van Gent, C.M.; Luten, J.B.; Ruiter, A. The Effect of various Intakes of Omega 3 Fatty Acids on the Blood Lipid Composition in Healthy Human Subjects. Am. J. Clin. Nutr. 1981, 34, 1752-1757. [PubMed]

52. Von Lossonczy, T.O.; Ruiter, A.; Bronsgeest-Schoute, H.C.; van Gent, C.M.; Hermus, R.J. The Effect of a Fish Diet on Serum Lipids in Healthy Human Subjects. Am. J. Clin. Nutr. 1978, 31, 1340-1346. [PubMed]

53. Ramprasath, V.R.; Eyal, I.; Zchut, S.; Shafat, I.; Jones, P.J.H. Supplementation of Krill Oil with High Phospholipid Content Increases Sum of EPA and DHA in Erythrocytes Compared with Low Phospholipid Krill Oil. Lipids Health Dis. 2015, 14. [CrossRef] [PubMed]

54. Montgomery, C.; Speake, B.K.; Cameron, A.; Sattar, N.; Weaver, L.T. Maternal Docosahexaenoic Acid Supplementation and Fetal Accretion. Br. J. Nutr. 2003, 90, 135-145. [CrossRef] [PubMed]

55. Velzing-Aarts, F.V.; van der Klis, F.R.; van der Dijs, F.P.; van Beusekom, C.M.; Landman, H.; Capello, J.J.; Muskiet, F.A. Effect of Three Low-Dose Fish Oil Supplements, Administered during Pregnancy, on Neonatal Long-Chain Polyunsaturated Fatty Acid Status at Birth. Prostaglandins Leukot. Essent. Fatty Acids 2001, 65, 51-57. [CrossRef] [PubMed]

56. Van Houwelingen, A.C.; Sorensen, J.D.; Hornstra, G.; Simonis, M.M.; Boris, J.; Olsen, S.F.; Secher, N.J. Essential Fatty Acid Status in Neonates After Fish-Oil Supplementation during Late Pregnancy. Br. J. Nutr. 1995, 74, 723-731. [CrossRef] [PubMed]

57. Connor, W.E.; Lowensohn, R.; Hatcher, L. Increased Docosahexaenoic Acid Levels in Human Newborn Infants by Administration of Sardines and Fish Oil during Pregnancy. Lipids 1996, 31, S183-S187. [CrossRef] [PubMed]

58. Haggarty, P. Fatty Acid Supply to the Human Fetus. Annu. Rev. Nutr. 2010, 30, 237-255. [CrossRef] [PubMed]

59. Hornstra, G. Essential Fatty Acids in Mothers and their Neonates. Am. J. Clin. Nutr. 2000, 71, 1262s-1269s. [PubMed]

60. Otto, S.J.; Houwelingen, A.C.; Antal, M.; Manninen, A.; Godfrey, K.; Lopez-Jaramillo, P.; Hornstra, G. Maternal and Neonatal Essential Fatty Acid Status in Phospholipids: An International Comparative Study. Eur. J. Clin. Nutr. 1997, 51, 232-242. [CrossRef] [PubMed]

61. Al, M.D.; van Houwelingen, A.C.; Hornstra, G. Relation between Birth Order and the Maternal and Neonatal Docosahexaenoic Acid Status. Eur. J. Clin. Nutr. 1997, 51, 548-553. [CrossRef] [PubMed]

62. Willett, W. Nutrional Epidemiology, 15th ed.; Oxford University Press: New York, NY, USA, 1990; p. 396. 